\title{
Vulvovaginal Self-care Under the Shadow of the Covid-19 Pandemic
}

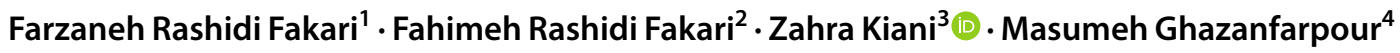

Received: 13 June 2021 / Revised: 29 June 2021 / Accepted: 29 June 2021 / Published online: 6 July 2021

(c) The Author(s), under exclusive licence to Springer Science+Business Media, LLC, part of Springer Nature 2021

Coronavirus (Covid-19), as a contagious respiratory disease, is spreading rapidly all around the world with various symptoms (World Health Organization, 2020). The recent outbreak of the virus in the world and the consequent quarantine and restrictions may lead to fear, worry, stress, anxiety, depression, and psychological reactions (Banaei et al., 2020; Fakari \& Simbar, 2020). Exposure to intermittent stress may increase the risk of vaginal infections (Amabebe \& Anumba, 2018). Hyperarousal is believed to be caused when the neurological pathways to the hypothalamus-pituitary-adrenal (HPA) axis—which regulates the stress response-become overly sensitized. When confronted with certain sensory stimuli, the HPA axis will overreact, triggering the secretion of excessive amounts of epinephrine which, in turn, stimulate the fear centers of the brain and chronic stress may lead to an infection, including vaginal infection (Amabebe \& Anumba, 2018). According to different studies, increased psychosocial stress is associated with increased bacterial vaginosis and candida vaginitis (Meyer et al., 2006; Nansel et al., 2006). During the Covid-19 epidemic, married women described vulvovaginal self-care as follows: despite having the annoying symptoms of a vaginal infection, some women did not refer to medical offices and hospitals because of the coronavirus and prevented vaginal infection through observing their hygiene, changing their underwear frequently, using loose cotton clothes, washing the perineum with soap and hygienic gels, and using fruits, supplements, and vitamins. Despite the Covid-19 pandemic, uncertain end of it, and

Zahra Kiani

zahra_kiani69@yahoo.com

1 Department of Midwifery, School of Medicine, North Khorasan University of Medical Sciences, Bojnurd, Iran

2 Student Research Committee, Department of Midwifery and Reproductive Health, School of Nursing and Midwifery, Shahid Beheshti University of Medical Sciences, Tehran, Iran

3 Sexual and Reproductive Health Research Center, Mazandaran University of Medical Sciences, Sari, Iran

4 Student Research Committee, Kerman University of Medical Sciences, Kerman, Iran the consequent limitations, self-care education is critically important in vaginal infections. In self-care education, nutritional education can be helpful in vaginal hemostatic mechanisms and the prevention of vaginal infections (Roberts et al., 2019). Moreover, pelvic floor and Kegel exercises may help to restore the strength of the pelvic floor muscles and prevent recurrent vaginal infections (Fang et al., 2018). Using a self-assessment test during the pandemic may also help diagnose the type of infection at home.

Online midwifery consultations and telephone midwifery triage are recommended in pandemic situations. Contact numbers should be provided to the public for online consultation and they should be informed in this regard. Moreover, the media, applications, and midwife voice telephone counseling can be used for self-care education. An inter-hospital communication system should be established for providing information about the number of patients so that patients can be referred to lower-risk hospitals for in-person examination and assessment. Additionally, if clients need an examination and in-person consultation, they should be informed about the examination time so that they do not contact each other at the time of referral.

Data availability The data that support the findings of this study are available from the corresponding author upon reasonable request.

Code availability Not applicable.

Declarations

Conflict of Interest The authors declare that there is no conflict of interest.

\section{References}

Amabebe, E., \& Anumba, D. O. (2018). Psychosocial stress, cortisol levels, and maintenance of vaginal health. Frontiers in Endocrinology, 24, 568. https://doi.org/10.3389/fendo.2018.00568

Banaei, M., Ghasemi, V., Saei Gharenaz, M., Kiani, Z., RashidiFakari, F., Banaei, S., Mohammad Souri, B., \& Rokni, M. (2020). 
Obstetrics and neonatal outcomes in pregnant women with Covid19: A systematic review. Iranian Journal of Public Health, 49, 38-47. https://doi.org/10.18502/ijph.v49iS1.3668

Fakari, F. R., \& Simbar, M. (2020). Coronavirus pandemic and worries during pregnancy; a letter to editor. Archives of Academic Emergency Medicine, 8, 21. https://doi.org/10.22037/aaem.v8i1.598

Fang, C., Yun-Jie, Y., Wen-jing, S., Xue-Ying, W., \& Le, M. (2018). Effect of pelvic floor muscle rehabilitation in preventing recurrent vulvovaginal candidiasis and recurrent bacterial vaginosis. Journal of Gynecology and Obstetrics, 6, 94-97. https://doi.org/10.3389/ fendo.2018.00568

Meyer, H., Goettlicher, S., \& Mendling, W. (2006). Stress as a cause of chronic recurrent vulvovaginal candidosis and the effectiveness of the conventional antimycotic therapy. Mycoses, 49, 202-209. https://doi.org/10.1111/j.1439-0507.2006.01235.x

Nansel, T. R., Riggs, M. A., Yu, K.-F., Andrews, W. W., Schwebke, J. R., \& Klebanoff, M. A. (2006). The association of psychosocial stress and bacterial vaginosis in a longitudinal cohort. American
Journal of Obstetrics and Gynecology, 194, 381-386. https://doi. org/10.1016/j.ajog.2005.07.047

Roberts, S. A., Brabin, L., Diallo, S., Gies, S., Nelson, A., Stewart, C., Swinkels, D., Geurts-Moespot, A., Kazienga, A., \& Ouedraogo, S. (2019). Mucosal lactoferrin response to genital tract infections is associated with iron and nutritional biomarkers in young Burkinabé women. European Journal of Clinical Nutrition, 73, 1464-1472. https://doi.org/10.1038/s41430-019-0444-7

World Health Organization. (2020). Novel coronavirus (2019-nCoV): Situation Report, 3. Retrieved from https://apps.who.int/iris/handle/10665/330762.

Publisher's Note Springer Nature remains neutral with regard to jurisdictional claims in published maps and institutional affiliations. 